\title{
Endoscopic ultrasonography-guided double-balloon-occluded gastrojejunostomy bypass (EPASS) for malignant gastric outlet obstruction
}

Our patient, a 58-year-old woman, was being followed-up for ulcerative colitis. Computed tomography (CT) showed the presence of a pancreatic nodule, which after endoscopic ultrasonography (EUS)guided puncture and biopsy was diagnosed as pancreatic head adenocarcinoma. The patient developed jaundice and acute cholangitis, and biliary drainage by endoscopic retrograde cholangiopancreatography was carried out.

One month later, the disease had progressed, with duodenal invasion and obstructive symptoms. Endoscopic palliation of the obstructive symptoms was opted for with EUS-guided double-balloon-occluded gastrojejunostomy bypass (EPASS) using a unique double-balloon tube (Tokyo Medical University type; Create Medic, Yokohama, Japan) and a novel electrocautery-tipped stent delivery system equipped with a lumen-apposing metal stent (Hot Axios stent; Boston Scientific, Marlborough, Massachusetts, USA) (\Fig.1). At follow-up, the patient presented good resolution of the obstructive symptoms and was referred for continuation of chemotherapy $(\triangleright$ Video 1$)$.

Surgical gastrojejunostomy, which has been the standard palliative treatment for malignant obstruction of the gastric outlet, is associated with good functional outcome and long-term relief of symptoms [1,2]. Endoscopic placement of a metal stent has been gaining popularity as an alternative to surgical gastrojejunostomy to treat malignant obstruction of the gastric outlet, because of its high technical success rates and lower degree of invasiveness [3].

To sum up, we established the feasibility of an EUS-guided gastrojejunostomy technique using a unique double-balloon tube and a novel electrocautery-tipped stent delivery system equipped with a lumen-apposing metal stent.

Endoscopy_UCTN_Code_TTT_1AS_2AB


- Fig. 1 a-d Procedure for endoscopic ultrasonography (EUS)-guided double-balloonoccluded gastrojejunostomy bypass (EPASS). a The guidewire is positioned. $\mathbf{b}$ EUS shows a distended jejunum. c Endoscopic imaging shows the distal flange of the biflanged lumenapposing metal stent in the jejunum. $\mathbf{d}$ Stent in place between the stomach and the jejunum.

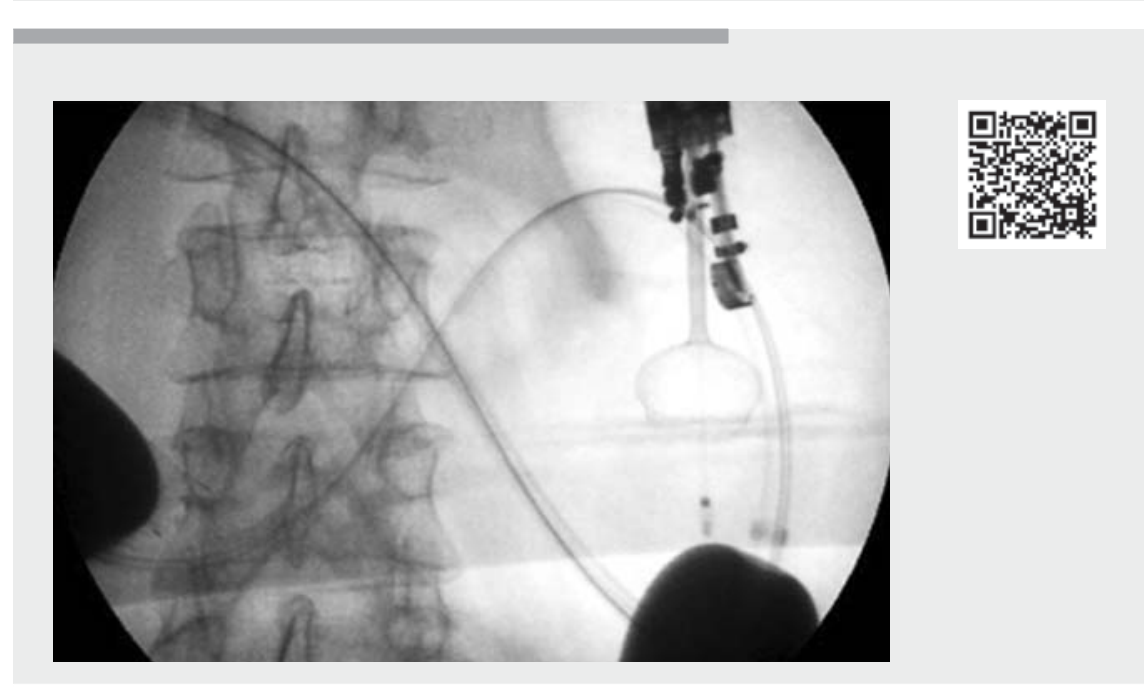

$\checkmark$ Video 1 Endoscopic ultrasonography-guided double-balloon-occluded gastrojejunostomy bypass (EPASS) for malignant gastric outlet obstruction. 


\section{Competing interests}

The authors declare that they have no conflict of interest.

The authors

John Alexander Lata Guacho, Marcelo Mochate Flor Marina Tucci G. B. Ferreira, Caio de Almeida Perez, Bruno da Costa Martins, Fauze Maluf-Filho ${ }^{\circ}$

Department of Gastroenterology, Endoscopy Division, Cancer Institute of the University of São Paulo, São Paulo, Brazil

Corresponding author

\section{Marcelo Mochate Flor, MD}

Department of Gastroenterology,

Cancer Institute of the University of São

Paulo, Av. Dr. Arnaldo, 251, São Paulo

01246-000, Brazil

mmochate@gmail.com

\section{References}

[1] Itoi T, Ishii K, Tanaka R et al. Current status and perspective of EUS-guided gastrojejunostomy - EUS-guided double-balloon-occluded gastrojejunostomy (EBOG). J Hepatobiliary Pancreat Sci 2015; 22: 3-11

[2] Binmoeller KB, Shah J. Endoscopic ultrasound-guided gastroenterostomy using novel tools designed for transluminal therapy: a porcine study. Endoscopy 2012; 44: 499-503

[3] Jeurnink SM, van Eijck CH, Steyerberg EW et al. Stent versus gastrojejunostomy for the palliation of gastric outlet obstruction: systematic review. BMC Gastroenterol 2007 7: 18

Bibliography

Endoscopy 2022; 54: E441-E442

DOI 10.1055/a-1625-2840

ISSN 0013-726X

published online 17.9.2021

(C) 2021. Thieme. All rights reserved.

Georg Thieme Verlag KG, Rüdigerstraße 14,

70469 Stuttgart, Germany
ENDOSCOPY E-VIDEOS

https://eref.thieme.de/e-videos



Endoscopy E-Videos is an open access online section, reporting on interesting cases and new techniques in gastroenterological endoscopy. All papers include a high quality video and all contributions are freely accessible online. Processing charges apply (currently EUR 375), discounts and wavers acc. to HINARI are available.

This section has its own submission website at

https://mc.manuscriptcentral.com/e-videos 